Revista do Programa de Pós-Graduação em Mídia e Cotidiano

Artigo Seção Dossiê Mídia e Cidade

Número 6. Volume 6 /Julho 2015

(C) 2015 by UFF

\title{
VER-SE COMO IMAGEM. BELEZA E ESTILO NOS MEDIA
}

\section{BEING AN IMAGE: BEAUTY AND STYLE IN THE MEDIA}

\section{Marta Maria CORDEIRO²}

Resumo: A liberdade e responsabilidade contemporânea na criação e difusão, por parte dos indivíduos, do seu estilo de vida implica importar para a designação de "estilo de vida" o conceito de beleza. A avaliação do "estilo" ou beleza depende das directivas fornecidas pelos media, especialmente através da sua comparação com as "celebridades", entidades que, ao serem reconhecidas publicamente, são adoptadas como modelos de conduta e de beleza. O mercado de massas apresenta a beleza como um conceito aparentemente democrático: qualquer indivíduo pode ser belo desde que se molde às directivas do mercado. $\mathrm{O}$ artigo problematiza a suposta democraticidade no acesso à beleza por parte dos indivíduos e foca a necessidade contemporânea dos indivíduos se verem, à semelhança das celebridades, como imagens.

Palavras-Chave: Estilo de vida; Beleza; Celebridades; Imagem; media;

Abstract: Contemporary responsibility in the creation and diffusion of images of one's life implies that the concept of beauty should be included in the definition of lifestyle. We compare ourselves and are constantly compared with the so called celebrities, entities that are publicly acknowledged and adopted as models of conduct and beauty. From this viewpoint, the evaluation of style and beauty depends on what the media determine. Mass market presents beauty as an apparently democratic concept, which any of us may possess (as long we, of course, adapt to the market's norms). This article discusses the supposed democracy in the access of images and argues that we need to see ourselves as images.

Keywords: Lifestyle; Beauty; Celebrities; Image; Media;

\footnotetext{
${ }^{1} \mathrm{O}$ artigo resulta da tese de Doutoramento de título O Corpo como Imagem e as Imagens do Corpo na Contemporaneidade, 2013.

${ }^{2}$ Doutora em Belas-Artes, especialidade em Teoria da Imagem pela Faculdade de Belas-Artes da Universidade de Lisboa. Professora no Departamento de Teatro da Escola Superior de Teatro e Cinema do Instituto Politécnico de Lisboa.
} 


\section{míDiA \\ ecO \\ DiAno}

\section{INTRODUÇÃO}

Na contemporaneidade, o corpo é o meio ou o lugar onde o indivíduo se projecta e constrói, de forma simultânea, facto que contrasta com a anterior submissão ao poder eclesiástico ou ao domínio das instituições modernas, especialmente representadas pelo Estado, pela Igreja e pela Família. O processo de autonomização do humano, iniciado na Renascença, desenvolve-se com a substituição do olhar omnipresente de Cristo, aos olhos de quem todos os corpos são iguais, pelo olhar humano, filtrado pelas instituições e que consagra a igualdade e liberdade de todos os indivíduos na Declaração dos Direitos do Homem e do Cidadão de 1789.

A outra face da liberdade é a da responsabilidade individual que, juntas, colocam a cada indivíduo a obrigatoriedade de fazer escolhas acerca de "quem é”. Neste sentido, Anthony Giddens (2001) fala da modernidade como processo de abandono das tradições que, embora constituam formas de apresentação de alternativas, estão longe de convocar a multiplicidade de opções oferecidas pela modernidade; por outro lado, o abandono da tradição corresponde à perda de um sistema de referências fechado onde as identidades individuais seguiam um percurso pré-determinado, em função de disposições (de sangue, género ou económicas) herdadas à nascença, para assunção dos riscos inerentes à escolha. Aqui, Giddens fala da identidade enquanto projecto em constante reformulação de acordo com as coordenadas veiculadas pelo contexto, processo não isento de ansiedades.

As escolhas espelham-se no denominado "estilo de vida", conceito que não se aplica às culturas pré-modernas por não ser transmitido ou herdado e se define na adopção de um conjunto de práticas que, enquanto respondem a necessidades operativas quotidianas, "dão forma material a uma narrativa particular de auto-identidade." (GIDDENS, 2001, p.75). Na prática, a liberdade moderna encontra-se restringida pelo poder das instituições e categorias estabelecidas e, para a afirmação plena do papel dos estilos de vida, foi necessária a consolidação do mercado de massas pós Revolução Industrial e a abertura à mobilidade social. 


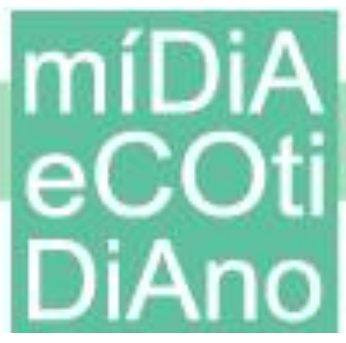

\section{Ter Estilo}

A centralidade do estilo de vida na construção contemporânea da identidade e a sua relação umbilical com o consumo é aceite na maioria dos debates, como mostra o artigo de David Bell e Joanne Hollows (2006), Towards a History of Lifestyle, que sumaria o pensamento de vários autores que abordam o tema. Os autores analisam o consumo no século XIX americano e observam que a estratégia de diferenciação dos "novos-ricos" foi feita através da ostentação do consumo de bens e de riqueza (em casas de campo, em festas, na criadagem mantida). Tal ostentação inclui, ainda, a exibição do acesso ao lazer através da figura da esposa: o homem que trabalha arduamente e proporciona a inutilidade à mulher; o ócio como "privilégio de uma vida desafogada" (ADORNO, 2003, p.133). Esta relação não é totalmente nova e Michel Foucault (2006) recorda que a concepção romana do otium se relaciona com o ócio e designa o tempo disponível para cuidar de si próprio, o que, na Grécia e Roma, é um privilégio das classes superiores; por oposição, os escravos ocupam o seu tempo a cuidar do património dos amos.

É neste contexto que Pedro Miguel Frade caracteriza a emergência da burguesia e a diferencia da nobreza, cuja distinção não é adquirida e, por isso, não depende da forma como o nobre é visto por terceiros: se o nobre se comportar publicamente de forma inadequada, ninguém dirá que deixou de ser nobre mas, antes, que perdeu a razão. Por oposição, a burguesia é uma conquista económica e simbólica e implica a figura "incómoda de uma veracidade sempre em falta" (FRADE, 1992, p.161), que se deve afirmar constantemente sendo vista. Para além do domínio económico, existe um lado público simbólico a cuidar e, por isso, a ordem burguesa inicia a união de "burguesia e parecer, ordem burguesa e império das aparências." (FRADE, 1992, p.160). Esta união estender-se-á aos cidadãos em geral por encontrar terreno fértil na organização das cidades que, ao albergarem populações de indivíduos indiferenciados, criam o desejo de diferenciação individual. A satisfação desse desejo realiza-se, em parte, através da lógica da aquisição de bens (muitas vezes resumida através da expressão "ter para ser"), fundamental para o sistema capitalista que depende da fluidez entre produção e consumo. 
Note-se que, mais que o acesso a bens materiais, está em causa a forma de utilização desses bens e a aproximação a capitais simbólicos pois a importância do estilo de vida coincide, como nota Pierre Bourdieu, com o processo de "estetização" da própria vida, onde prevalece a forma sobre a função e onde é determinante a capacidade de obtenção de status: "E nada é mais distintivo, mais diferenciador, que a capacidade de conferir estatuto estético a objectos que são banais ou até "comuns", ou a aptidão para aplicar os princípios da estética "pura" à maioria das escolhas da vida quotidiana." (BOURDIEU, 1984, p.5).

O status, que Max Weber (1978) alia à definição marxista de classe, depende da obtenção de uma "estima social", um privilégio que Bourdieu associa a uma existência protegida de privações económicas e na qual se observa a satisfação das necessidades. Nesta análise, as "necessidades" revestem-se de um carácter utilitário (ou primário) quando, por seu turno, Jean Baudrillard (1982) rejeita a existência de necessidades primárias e secundárias, fazendo depender qualquer delas das exigências do sistema produtivo. $\mathrm{O}$ autor nega o consumo enquanto factor de mobilidade social, afirmando que este apenas mascara a ideologia e contribui para a manutenção das hierarquias sociais em função das diferenças no discurso dos objectos e bens; esta posição contesta a tese de que, ao consumir, o indivíduo goza de alguma liberdade que lhe permite ultrapassar a condição herdada.

As limitações que Baudrillard observa prendem-se, por um lado, com o acesso a determinados bens e, por outro, com a sua forma de utilização que, como mostra o seu exemplo da casa pequeno-burguesa repleta de bibelots, se transforma numa necessidade de acumulação de coisas redundante que mascara, afinal, a interdição à ascensão social. Ainda assim, o consumo permite a construção de uma imagem por parte dos indivíduos que, potencialmente e apesar de todas as limitações, expressa aquilo que é uma construção particular - a identidade traduzida por um estilo de vida que tudo integra: status, gostos, saúde, aspirações e desejos, lazer e que transporta a promessa de que podemos melhorar-nos.

A obtenção de "estima social" é cada vez mais tida como resultado de um investimento do sujeito em si, cujo efeito depende da visibilidade: Zygmunt Bauman 


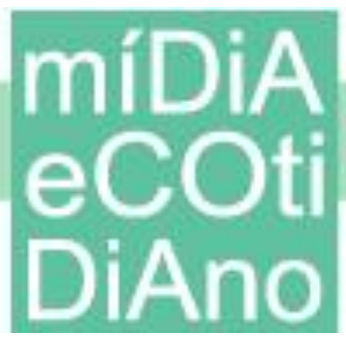

(1995) fala da passagem dos desígnios sociais comuns para a adopção do estatuto de "micro-empresas" pelos indivíduos, que particularizam desejos e aspirações e fazem do corpo o objecto de investimento primordial [o mais belo objecto de consumo, como diria Baudrillard (1995, p.136)], apostando na possibilidade de o transformar e melhorar de forma a expressar a personalidade. Neste contexto, o corpo confunde-se com a aparência e interessa aprofundar a relação entre essa superfície e a personalidade quando a última perde o seu estatuto imutável, como subentendia no significado do termo carácter, para se transformar ela própria na manipulação e apresentação de códigos sociais inscritos no corpo. Quando verifica o fim do corpo "metafórico" e a emergência do corpo "metamórfico", Baudrillard (1988) assume que o corpo perde a justificação transcendental ou narrativa para se transformar num objecto de pura sedução, onde a capacidade de alteração da forma o leva a desaparecer - desaparecer é dispersar-se nas diversas aparências. É, ainda, a sedução que Mike Featherstone (1991) alia à personalidade, com a sua capacidade de ser atractiva, magnética ou fascinante, adjectivos maleáveis que contrastam com o dever, honra, integridade ou moral que se associa ao carácter. A personalidade alia-se à performance - que conta com a capacidade de ser agradável para terceiros - e encontra a sua consagração no culto das personalities, instituído por Hollywood nas primeiras décadas do século XX.

A passagem do "carácter" à "personalidade" corresponde a uma alteração do paradigma social que coloca o indivíduo no lugar central e que, na prática, substitui a ideologia pela identidade. A identidade que Giddens trata de forma particular - a de cada sujeito - é pensada por Walter Benn Michaels (2004) na forma de modelo de organização social: como o carácter, a ideologia é boa ou má e crê-se que a "minha ideologia" é melhor que todas as outras. Esta vocação universal ostraciza o que lhe é antagónico quando, por oposição, a identidade assume um carácter particular, é "de cada um" e não existe necessidade de a pensar em termos exclusivos. Ainda assim e por se fundar na convicção, a ideologia pode ser alterada quando a identidade, por definir “quem se é", não pode - por este motivo se fala da centralidade do sujeito. Michaels (2006) analisa o paradigma da identidade através da sua comparação com o da raça (categoria que começa por desconstruir questionando a sua cientificidade): actualmente, 


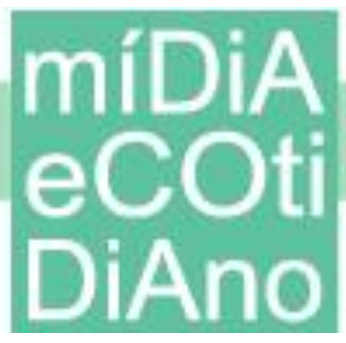

afirma, é condenável ser racista e é politicamente incorrecto considerar que uma raça é melhor que outra; pelo contrário, incentiva-se a diferença e valoriza-se a raça como capital cultural (conceito que o autor também questiona, afirmando não existirem práticas, aprendizagens e gostos comuns a todos os indivíduos de uma raça). Ao pensar a adaptação deste modelo à análise das classes, afirma que se passou a considerar não existirem diferenças entre pobres e ricos quando, na verdade, as diferenças existem e não é indiferente ter ou não dinheiro: é melhor ser rico. Mas a adopção do modelo das identidades (e da raça) leva a crer que o importante é que cada sujeito, individualmente, trate os pobres como iguais e não seja classista, em vez de lutar para fazer terminar a desigualdade.

Este modelo aparentemente democrático aceita a desigualdade enquanto ilude a igualdade entre indivíduos e a sua capacidade de escolha. Depois, a ampliação do leque de opções em função do incentivo da diferença alimenta a criação de um mercado onde qualquer indivíduo encontra um lugar como consumidor. Se se aplicar o modelo à aparência, verifica-se a repetição do predicado de que "todos são belos" e de que a beleza está ao alcance de qualquer um; de uma concepção de beleza que estabelece hierarquias e é exclusiva, passa-se ao conceito alargado de "interessante", que não integra necessariamente a beleza mas se adapta ao mercado por ser "um conceito consumista (...) quanto mais as coisas se tornam interessantes, mais o mercado cresce." (SONTAG, 2007, p.10).

Enquanto os modelos únicos ou restritivos desqualificam, à partida, um largo número de potenciais consumidores, a estratégia da identidade promete aceitar todos os indivíduos. Nesta definição de "beleza-interessante" encontra-se o "estilo", a fórmula simplificada do "estilo de vida" que contribui para considerar alguém belo. Acontece que o estilo e a beleza devem expressar a personalidade, que não é boa ou má, é a de cada um; quanto ao estilo, "tem-se" ou "não se tem" e, quando um indivíduo "não tem estilo", deve socorrer-se dos meios necessários para construir um que possa revelar a sua personalidade escondida. A questão está no acesso aos meios e na forma como, ao aceitar todas as identidades e belezas como igualmente válidas, se esconde a desigualdade no acesso aos capitais e bens capazes de construir os "estilos de vida" de 


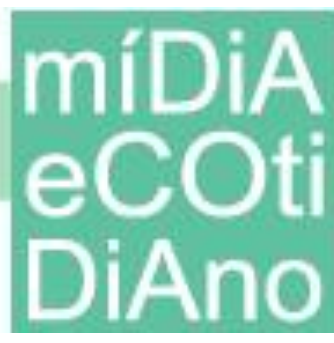

sucesso. A adesão entre estilo de vida e beleza aproxima, definitivamente, a última do consumo e faz qualquer deles depender da possibilidade real de estetizar a vida de que fala Bourdieu.

\section{O Exemplo das Celebridades}

"Nos contextos pós-tradicionais, não podemos senão escolher como ser e como agir." (GIDDENS, 1994, p.75). O imperativo da escolha gera sentimentos de insegurança que motivam o aparecimento e recorrência a experts, entidades ou personalidades modelo de quem os indivíduos se socorrem para, de entre os propostos, escolherem a adopção de determinados estilos de vida. Giddens reconhece a importância da experiência mediada e a autoridade das designadas figuras públicas que, como Stephen Hinerman (2001) argumenta, substituem o papel antes consagrado aos heróis literários na difusão de estilos de vida positivos. Hinerman considera, ainda, que o fascínio pelos famosos e a aspiração à fama não é uma novidade contemporânea e que é transversal à História: muitas das palavras associadas ao actual star system - fama, ambitio, celebritas - remontam ao mundo romano e à fama encontra-se associado o poder e o sucesso. É razoável, então, legitimar as escolhas individuais através das observadas nas celebridades, como é exemplo o concurso televisivo Style Her Famous. Neste programa, as participantes concorrem a uma alteração da aparência e, guiadas pelo consultor de moda Jay Manuel, seleccionam uma celebridade modelo. O objectivo é alterarem a sua aparência de forma a que esta se assemelhe à da modelo seleccionada. A partir desse momento, procede-se às transformações de vestuário, maquilhagem e cabelo e, como resultado, as concorrentes protagonizam uma sessão fotográfica com um fotógrafo de moda. Nesse momento, dá-se a transformação do indivíduo em imagem, momento que é a consagração de uma mudança - do "não ter estilo" para o ter, do ser desinteressante para interessante ou belo.

A utilização da imagem como forma de ascensão contamina a história do retrato, nascido da pintura e apenas acessível, numa primeira fase, às classes privilegiadas. A prática do retrato encontra-se umbilicalmente ligada ao culto do indivíduo e encontra eco nas fotografias de André Disderi (1819-1889) que, ao inventar uma forma menos 


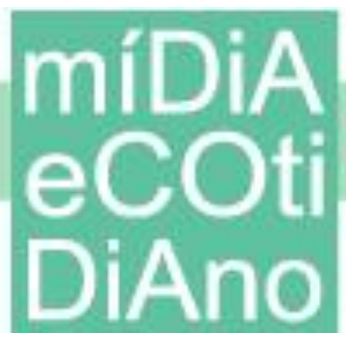

dispendiosa de produção de fotografias, estende a prática à burguesia e ao proletariado. Na prática, Disderi substituiu a chapa pelo vidro e diminuiu a escala das imagens, conseguindo dez fotografias de $6 \times 9 \mathrm{~cm}$ numa só placa. Disderi democratizou os "cartões-de-visita" (carte-de-visite), onde indivíduos eram normalmente fotografados de corpo inteiro, frente a um cenário. Aí, a luz, os figurinos e os acessórios (uma coluna para apoiar o braço, um pequeno livro, uma tapeçaria como fundo) eram criteriosamente encenados de forma a dotar cada indivíduo de sinais distintivos de uma classe; independentemente da verdadeira procedência, adoptava uma identidade social burguesa ["De onde vêm eles? Duma família de notários do Alto-Garona. Eis-me ali integrado numa raça, numa classe." (BARTHES, 1975, p.26)]. A imagem fornece o meio para encenar, para a posteridade, um estatuto merecedor de "estima" da mesma forma que a sessão fotográfica que Jay Manuel propõe aproxima as concorrentes da celebridade eleita e deixa, também para a posteridade, a prova de que é possível mudar e ser belo; é possível ascender, mesmo que momentaneamente, ao estatuto das celebridades e merecer, igualmente, a fama, o status e o sucesso.

Terá sido a estratégia de mercado de pequenas indústrias o embrião do starsystem: Richard DeCordova (1990) fala da aposta na persuasão dos espectadores através da imagem das estrelas. Inicialmente, a discussão limitava-se à performance no ecrã e a uma personalidade construída pelos vários desempenhos, unidos através de um nome; 1913 é apontado como o ano a partir do qual a imprensa passa a noticiar a vida privada das estrelas, justificando a definição proposta por John Ellis, "um performer de um médium particular cuja figura entra em formas de circulação subsidiárias, e alimenta futuras performances.” (1982, p.91). Da associação entre o ecrã e o quotidiano emerge uma personalidade pública que, na raiz do sucesso, conta com o fascínio da imagem, o encanto e a qualidade do desempenho. Estas qualidades justapõem-se no caso particular dos modelos em que a qualidade do desempenho se encontra firmemente ligada à aparência, à beleza da sua imagem e à atractividade ou carisma. A função do modelo é, ao mesmo tempo, cativar com o corpo (a beleza e gestualidade do corpo, o magnetismo do olhar) e, paradoxalmente, suspender-se de forma a atribuir importância e visibilidade ao objecto que apresenta, de tal forma que são as qualidades implícitas no objecto que 


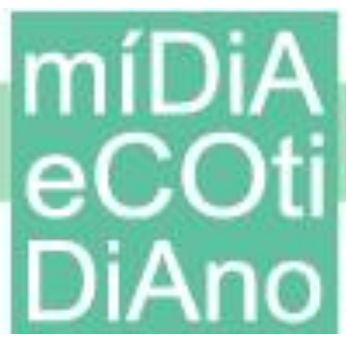

determinam a "personalidade" interpretada. É este "estado de suspensão" que faz com que, quando um modelo se torna uma celebridade, deixe de poder posar de forma "neutra" e que, nessa circunstância, a apresentação do produto passe a beneficiar directamente das qualidades associadas à celebridade em causa. Mas, nos modelos anónimos, é como superfície em exposição (a exposição que escapa à oposição entre valor de uso e valor de troca ) que o corpo é desvelado e, no limite, é ele a pura superfície que Baudrillard (1993) encontra nas réplicas de Marilyn Monroe de Andy Warhol, que acusam a morte do original e da representação para serem apenas imagens de imagens de imagens.

\section{Ver-se como Imagem}

É recorrente, nos desenhos animados, o episódio em que, num dado momento, o personagem chega ao fim de um percurso e, por não olhar para baixo, continua a caminhar no vazio; quando olha para baixo e se apercebe da falta do chão, cai no abismo. A lógica destas situações é a de que basta acreditar no impraticável para o concretizar e que, no interior das imagens, tudo é possível.

Diz-se das celebridades que o sistema de comunicação de massas as aparta do seu "verdadeiro eu" e as transforma num produto, numa imagem e, simultaneamente, que têm a capacidade de ultrapassar os limites do quotidiano, contribuindo para a definição de objectivos no projecto identitário dos indivíduos. Estudos mostram que, quando comparam as suas vidas com as apresentadas no ecrã, os espectadores sentem-se desapontadas com a sua realidade, especialmente no âmbito do romance, sexualidade, carreira mas, também, beleza, juventude e felicidade . Numa época onde o Paraíso celeste ou a perfeição social moderna foram substituídos pelos objectivos privados de realização pessoal e qualidade de vida (BAUMAN, 1995), as imagens modelo das celebridades, onde se misturam as personagens com o real, apresentam versões melhoradas do quotidiano, onde as emoções são mais intensas (nos momentos bons e maus), a vida tem maior drama, surpresa, glamour e é a este espaço que se deseja aceder, mesmo que momentaneamente. Esta possibilidade da imagem apresentar o irreal ou o real melhorado aponta para o significado da palavra representação, literalmente 


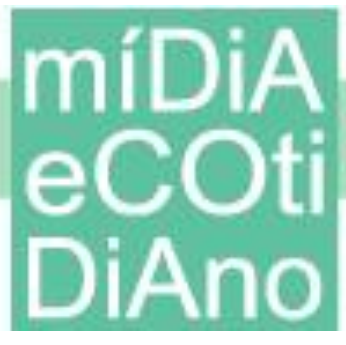

"voltar a apresentar" mas, também, "estar em vez de". Este "estar em vez" refere-se tanto ao visível (que existe), como ao invisível, que tanto pode ser aquilo que, sendo visível porque existe se encontra ausente, como aquilo que não existe e, ao ser representado, é criado e concretizado, fazendo justiça ao seguimento da definição de "representação" que também se define como apresentar-se ao espírito ou imaginar-se.

A felicidade que as concorrentes encontram durante e quando visionam os resultados das sessões fotográficas de Style Her Famous resulta da oportunidade de integrar o mundo das imagens do estrelato, onde tudo é possível e melhor e, ainda, da capacidade de "saírem de si" e verem-se como imagens. Esta possibilidade é enfatizada num outro programa televisivo, Tim Gunn's Guide to Style, onde o software OptiTex simula digitalmente a imagem tridimensional dos concorrentes e permite ensaiar visuais alternativos através de alterações do vestuário, da maquilhagem e do cabelo. Na maioria dos episódios, os concorrentes mostram-se surpreendidos com a sua imagem e consideram-na melhor do que originalmente pensaram - é nesta imagem dominada pela distância de observação que reside a promessa de reencontro entre um "eu" idealizado e construído através da imagem e de uma aparência regenerada.

Nestas imagens reside o paradoxo que o personagem Antonino Paraggi, de A Aventura de um Fotógrafo de Italo Calvino, expõe a propósito da fotografia: "O passo entre a realidade que é fotografada na medida em que nos parece bonita e a realidade que nos parece bonita na medida em que foi fotografada é curtíssimo." (1992, p.54). É a verdade que fica entre estas duas perspectivas que Paraggi persegue nos retratos que faz, obsessivamente, da sua modelo Bice e que, até ao momento em que Bice o abandona, não encontram a verdadeira imagem da mulher: entre a captura de um instante de espontaneidade e a encenação da pose onde também se dá a ver a verdade da máscara (a máscara como produto histórico e social onde, como nos retratos de Disderi, se revelam significados íntimos na forma de usar a roupa ou pentear o cabelo).

Quando Bice parte, Paraggi continua a fotografar o vazio deixado pela modelo, até ao momento em que descobre que a única possibilidade que lhe resta é fotografar fotografias compostas por diversos fragmentos - a verdadeira imagem, a "fotografia total", apenas se encontra na justaposição de fragmentos da vida privada cuja realidade 


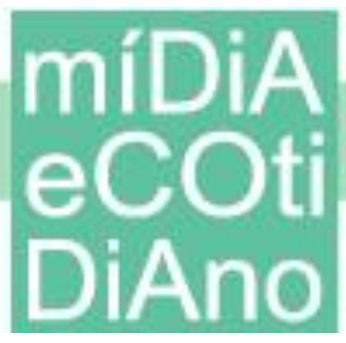

é já a da imagem. Paraggi acredita que aquilo que perdura - e por isso existe - é aquilo que é imortalizado pela fotografia. Esta existência na imagem é mais estranha no caso do corpo que apenas pode existir sendo visto, para o próprio indivíduo, como imagem e que, actualmente, tem como modelo outros corpos transformados em imagens. A vertigem deste corpo-em-abismo é a de um abismo que não cessa de oferecer imagens e onde a coincidência entre o corpo próprio e o corpo modelo está longe de ser total e, por isso, final. É sempre numa (outra) imagem que o sujeito espera reconhecer-se e o apelo da imagem consagrada como celebridade é, sendo aceite por terceiros (um público que faz do indivíduo um objecto espectacular e, em simultâneo, lhe garante um lugar no interior de um grupo, como membro), ser aceite pelo próprio como sendo assim:

Mas eu nunca fui assim! - Como sabe? (...) Sois o único que não pode nunca ver-vos senão em imagem, nunca vedes os vossos olhos senão embrutecidos pelo olhar que projectam no espelho ou na objectiva (interessar-me-ia apenas ver os meus olhos quando te olham): mesmo e sobretudo para o vosso corpo, estais condenado ao imaginário. (BARTHES, 1975, p44).

\section{Considerações Finais}

Tendo em consideração a oportunidade e obrigatoriedade contemporânea de realizar escolhas acerca de quem é, o indivíduo expressa essas escolhas na construção de um estilo de vida, que não pode ser afastado dos mecanismos de consumo de bens materiais e capitais simbólicos, responsáveis pela obtenção de status social; o "estilo" é, em grande parte, uma espécie de "curriculum vitae visual". O mercado difunde a mensagem de que "ter estilo" está ao alcance de todos, o que faz com que se democratize o acesso ao "estilo" e que todos os indivíduos passem a ser potenciais consumidores; no entanto, o acesso aos capitais necessários à construção de um estilo de vida considerado de sucesso depende da existência de recursos económicos que permitam realizar a relação "ter para ser", disponibilidade que não é comum a todos os indivíduos. "Ter estilo" é uma forma sucedânea de "ser belo", pois o conceito de beleza foi alargado, tornando-se mais abrangente e móvel e adaptado a um mercado que necessita de criar necessidades constantemente: "A característica daquilo que é 


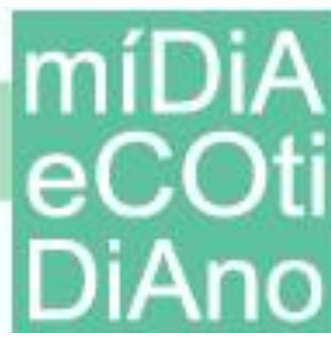

"interessante" é que isso pode, já a partir do instante seguinte, ter-se tornado indiferente para nós e ser substituído por outra coisa, que nos diz tão pouco respeito quanto a precedente." (HEIDEGGER, 1983, p.23 apud FRADE, 1992). Em simultâneo, "ser belo" é expressar a personalidade, conceito que substitui a rigidez relacionada com o carácter moderno e que se adequa a uma estrutura que conta com as designadas celebridades como modelos de conduta e de beleza. Numa época em que responsabilidade e ansiedade andam a par, as celebridades funcionam como pontos de apoio e ancoragem que auxiliam a construção dos percursos dos indivíduos pois, por serem reconhecidas, são exemplos sancionados publicamente.

Definir as celebridades como imagens decorre do facto da sua divulgação através dos media seguir o curso da divulgação de todos os outros produtos e comodidades por eles difundidos. Acresce o facto da valorização das celebridades depender, como defende Daniel Boorstin (1962), de serem conhecidas, ou seja, do facto de aparecerem e, através dos media, aparecerem como imagens que fascinam. Estudos mostram que os indivíduos consideram que as suas vidas não possuem o encanto das vidas divulgadas pelos media e a influência das celebridades integram-se nessa lógica: o indivíduo projecta-se e permite-se efabular sobre um momento realizado à semelhança daqueles que os media apresentam. Esta possibilidade de tornar presente o inexistente pertence ao domínio das imagens e, nessa circunstância, os indivíduos aspiram ver-se como celebridades e ver-se como imagens para, através delas, se aceitarem sendo assim e serem aceites pela comunidade. Note-se que a possibilidade de se relacionar com uma imagem através da sua contemplação é uma capacidade que, como afirma Rosalind Krauss (1999, p.90), pertence aos humanos; ver-se como imagem é uma derivação desta qualidade que acrescenta a capacidade de, vendo-se, projectar-se e aceitar-se sendo assim. 


\section{míDiA \\ ecO \\ DiAno}

\section{REFERÊNCIAS}

ADORNO, T. W. Sobre a Indústria da Cultura. Coimbra: Angelus Novus, 2003.

AGAMBEN, G. Profanações. Lisboa: Livros Cotovia, 2006.

BARTHES, R. Roland Barthes por Roland Barthes. Lisboa: Edições 70, 1975.

BAUDRILLARD, J. A Sociedade de Consumo. Lisboa: Edições 70, 1995.

BAUDRILLARD, J. Para uma Crítica da Economia Política do Signo. Lisboa: Edições 70, 1982.

BAUDRILLARD, J. Symbolic Exchange and Death. London: Sage Publications, 1993.

BAUDRILLARD, J. The Ecstasy of Communication. New York: Semiotext(e), 1988.

BAUMAN, Z. Life in Fragments: Essays in Postmodern Morality. Cambridge: Blackwell, 1995.

BELL, D., HOLLOWS, J. - Towards a History of Lifestyle. In: BELL, D., HOLLOWS, J. (Ed.) Historicizing Lifestyle: Mediating Taste, Consumption and Identity from 1900s to 1970s. Hampshire: Ashgate Publishing Ltd., 2006.

BOORSTIN, D. The Image: a Guide to Pseudo-Events in America. New York: AthEneum, 1962.

BOURDIEU, P. Distinction: a Social Critique of the Judgement of Taste. USA: Routledge \& Kegan Paul Ltd., 1984.

CALVINO, I. A Aventura de um Fotógrafo. In: Amores Difíceis. São Paulo: Companhia das Letras, 1992.

DECORDOVA, R. Picture Personalities: The Emergence of the Star System in America. Urbana: University of Illinois Press, 1990.

ELLIS, J. Visible Fictions: Cinema, Television, Vídeo. London: Routledge, 1982.

FEAHERSTONE, M. The Body in Consumer Culture. In: FEATHERSTONE, M., HEPWORTH, M., TURNER, B.(Ed.) The Body: Social Process and Cultural Theory. London: Sage Publications, 1991.

FOUCAULT, M. A Hermenêutica do Sujeito. São Paulo: Martins Fontes, 2006.

FRADE, P. M. Figuras do Espanto: a Fotografia antes da sua Cultura. Porto: Asa, 1992.

HINERMAN, S. Star Culture. In: LULL, J. (Ed.) Culture in the Communication Age. New York : Routledge, 2001. 
KRAUSS, R. Gestalt. In: BOIS, Y-A., KRAUSS, R. Formless: a User's Guide. New York: Zone Books, 1999.

MESSARIS, P. Visual Culture. In: LULL, J. (Ed.) Culture in the Communication Age. New York : Routledge, 2001.

MICHAELS, W. B. The Shape of the Signifier: 1967 and the End of History. Princeton \& Oxford: Princeton University Press, 2004.

MICHAELS, W. B. The Trouble with Diversity: How to Learn to Love Identity and Ignore Inequality. New York: Metropolitan Books, 2006.

SONTAG, S. At the same Time: Essays and Speeches. New York: Farrar Straus Giroux, 2007.

WEBER, M. Economy and Society. California: University of California Press, 1978. 